\title{
A recepção de Pierre Bourdieu no Brasil: Circunstâncias e Mediadores ${ }^{1}$
}

Sergio Miceli

$E_{m}$ atenção ao pedido da professora Maria Tarcisa Bega de falar aos alunos e professores do Programa de Pós-Graduação em Sociologia da Universidade Federal do Paraná, quero retomar o trabalho que apresentei em Paris no primeiro semestre deste ano, em seminário organizado pelo Centre National de la Recherche Scientifique (CNRS), em torno da recepção da obra de Pierre Bourdieu nas Américas - inclusive o Brasil. O texto foi debatido em mesa redonda com outros colegas: Francine Muel-Dreyfus havia realizado uma investigação a respeito da seita Vale do Amanhecer em Brasília, em perspectiva comparada com movimento similar na capital francesa; Monique de Saint-Martin veio ao país várias vezes, onde desenvolveu linhas de investigação, tendo abordado trechos das cartas que Bourdieu lhe endereçou nessas viagens; ambas visitaram o Brasil a meu convite e são diretoras de estudos (hoje aposentadas) na Escola de Altos Estudos em Ciências Sociais; Yves Winkin esboçou um relato da recepção de Bourdieu nos Estados Unidos. O título A recepção de Bourdieu no Brasil: circunstância e mediadores - é o mesmo da conferência hoje.

Começo pelas precauções que me parecem indispensáveis. A primeira se refere à defasagem temporal: agora tenho 74 anos, mas tinha apenas 29 anos quando cheguei em Paris, em 1974, para iniciar o doutorado com Bourdieu, em plena vigência da ditadura militar no Brasil. Não posso me eximir de elaborar o relato retrospectivo sobre a recepção e o impacto da obra do mestre no Brasil, na condição de professor da Universidade de São Paulo (USP) há mais de 30 anos - posição institucional de relevo no campo intelectual nativo e inseparável de certo status na sociologia brasileira. Não é possível nublar tais liames. Na minha geração, outros intermediários e difusores locais da obra de Bourdieu também o fizeram bem jovens, no início da carreira acadêmica, em momento bem

\footnotetext{
1 O texto a seguir advém da Aula Magna do Programa de Pós-Graduação em Sociologia da Universidade Federal do Paraná, ministrada pelo autor em agosto de 2019.

2 Professor Titular do Departamento de Sociologia da Universidade de São Paulo.
} 
distinto no tocante às condições de competição no campo. Por conseguinte, cumpre intentar o esforço, nem sempre bem-sucedido, de restaurar de algum modo as perspectivas que possuíamos na década de 1970, o começo do imbróglio. Senão, corro o risco de simular um sobrevoo pretensamente abrangente, não por acaso em linha de como estou hoje enxergando o que sucedeu.

Houve dois momentos de recepção no Brasil: a largada, nos anos 1970 e 1980; a segunda rodada nos anos 1990 e 2000 - quando a pós-graduação em sociologia já fora implantada em escala nacional, agregando intermediários que não serão aqui aludidos. Não se pode borrar o lugar que modela nossa voz, problema incontornável em sociologia.

A segunda precaução tem a ver com o envolvimento apaixonado no processo. Não posso fingir que apreendo o que se passou objetivamente; como agente interessado no êxito da recepção, alguém engajado de cabeça no trabalho, vocês devem equacionar o relato levando em conta o enlace pessoal, afetivo e enviesado. Fiz o doutorado em Paris, onde morei três anos, tendo retornado várias vezes e, claro, tive uma relação próxima com Bourdieu, em momento inicial de arranque em trajetória meteórica. Tais evidências não constituem, de minha perspectiva, dados objetivos de pesquisa. Tudo que vou dizer está enredado nessa experiência, no fato de sempre ter sido parte do jogo.

Antes de prosseguir, convém qualificar a posição peculiar do Brasil no contexto global de recepção da obra. Medido por indicadores usuais, o caso brasileiro é de fato expressivo: trata-se do autor estrangeiro mais citado na ciência social brasileira, ao lado de Michel Foucault. Alcançou aqui maior repercussão do que nos Estados Unidos, onde não desfrutou da mesma posição hegemônica entre autores estrangeiros traduzidos.

Quero ressaltar as linhas de força da recepção, para que se possa atinar por que sucedeu assim. A coordenada de fundo tem a ver com a história das ciências sociais - em especial, da sociologia - no Brasil. A obra de Bourdieu não caiu do céu e, de supetão, encaixou-se na cena intelectual brasileira. Cumpre recuperar a história da Sociologia, em especial na Universidade de São Paulo, e restituir o clima de guarida mesclado à hostilidade, de aceite e recusa. Veremos, ao longo da conversa, como isso ocorreu.

Alguns dados são relevantes com vistas a recuperar a história da sociologia. Como se sabe, houve uma missão francesa na USP, com intelectuais prestigiosos em ciências sociais -, Fernand Braudel e Claude Lévi-Strauss, entre outros. No entanto, no caso da 
sociologia, Roger Bastide foi a figura de maior peso no trabalho da missão, o mais consequente para o tema de hoje.

Bastide morou 15 anos no Brasil. Retornou à França apenas em 1959 e teve impacto graúdo na Universidade de São Paulo. Exerceu influência marcante não apenas entre cientistas sociais, mas também junto ao círculo de jovens congregados no grupo Clima, que se tornaram críticos e historiadores da arte e da literatura brasileira: Antônio Cândido, Décio de Almeida Prado, Gilda de Melo e Sousa, Paulo Emílio Salles Gomes, Lourival Gomes Machado, Rui Coelho etc. Quase todos formados em Ciências Sociais, muitos deles iniciaram a carreira como sociólogos, mas foram se especializando em história da arte, história e crítica literária, cinema, teatro. Foram alunos devotados de Bastide. O lastro sociológico das obras produzidas pelo grupo Clima provém dessa raiz. Ademais, Bastide se aprofundou em estudos de assuntos centrais para a cultura brasileira: investigou as religiões populares, em especial o candomblé; escreveu ensaios originais sobre autores de peso em nossa tradição poética - Mário de Andrade, Guilherme de Almeida, Cruz e Sousa; adquiriu domínio seguro da língua portuguesa, embora tenha encomendado a tradução de seus textos no início da estadia. Há relatos de que se expressava com fluência em português. O germe da sociologia da cultura remonta à sua presença na Universidade de São Paulo. Na França, ele nunca se equiparou a Braudel ou a Lévi-Strauss em matéria de prestígio intelectual. Tamanho desapreço não se deve à falta de obra de folego, inventiva e fora de esquadro. O jovem Bourdieu escreveu resenha sobre um livro de Bastide. Decerto atinou com a substância da obra e reconhecia o valor do autor. Bastide não recebeu aí o mesmo reconhecimento logrado no Brasil por conta de feições da obra, cujos objetos e problemáticas se referiam à sociedade brasileira, e da inserção tardia no universo intelectual francês.

No Brasil, a publicação de A Economia das Trocas Simbólicas (1972)33 sucedeu em momento de declínio da influência francesa, com a diminuição do número de pessoas que sabiam e falavam francês nos círculos de elite. Também vale considerar a ascensão da ciência social norte-americana, com influência crescente em ciência política e

3 BOURDIEU, P. A economia das trocas simbólicas. Introdução, organização e seleção Sergio Miceli. São Paulo: Perspectiva, 1972.361 p. 
antropologia e, logo adiante, o arranque no financiamento da Fundação Ford ao fomento dessas áreas no país. Até então, no âmbito da Universidade de São Paulo, a sociologia persistia como disciplina dominante: dispunha de número expressivo de professores titulares, se comparado à antropologia e à ciência política; idêntica desproporção se aplicava ao tamanho do corpo docente. Os indicadores da hegemonia sociológica foram reforçados pela liderança de Florestan Fernandes e dos discípulos. Logo mais, a antropologia lograria se autonomizar como disciplina, e o mesmo sucedeu com a ciência política, a qual não tardou a se americanizar em detrimento do interesse pregresso pela história política brasileira.

Tal cenário ajuda a recuperar a atmosfera intelectual da época, bem como a rastrear os autores e as influências em meio aos quais os integrantes dessa geração foram treinados. Qual a vivência cultural como alunos de pós-graduação? Havia a predominância inconteste do marxismo na universidade. A hegemonia marxista na área cultural se encarnava na figura reverenciada de Antônio Gramsci, com textos traduzidos e publicados então pela Editora Civilização Brasileira, inclusive os Cadernos do Cárcere (escritos entre 1929 e 1935). Os cursos consagrados a Gramsci eram estáveis na grade. Um trabalho de aproveitamento se converteu no meu artigo de estreia, em revista da área de educação: tratava-se de um fichamento pretensioso da obra de Gramsci, no qual discorria sobre o tema dos intelectuais. Se quisessem se mostrar afinados e competentes em termos de teoria, em matéria conceitual, os alunos se viam instados a conquistar domínio seguro dos escritos do pensador italiano. Éramos todos comentaristas de Gramsci, obcecados pela ideia de intelectual orgânico, pelo conceito de hegemonia e, a tábua de salvação, pelos aparelhos do Estado.

Havia ainda, em disparo de ascensão, a moda do estruturalismo; em paralelo a Gramsci, a antropologia estrutural de Lévi-Strauss; a dialética marxista de Louis Althusser, de epígonos na metrópole (Nicos Poulantzas) e na América Latina (Martha Harnecker). Devorávamos tais textos como livros de missa, guias de orações. Sabíamos de cor o primeiro capítulo de $O$ Capital. Sob chancela do estruturalismo não marxista, Antropologia Estrutural, originalmente publicado em 1958 por Lévi-Strauss, era obra compulsória. Líamos Lévi-Strauss, Roland Barthes e, de arrastão, outras figuras do 
estruturalismo francês não marxista. Despontavam a semiologia e a linguística. Referências que ajudam a pautar o universo intelectual da geração.

Minha tese de mestrado a respeito da apresentadora de televisão Hebe Camargo - A Noite da Madrinha: Ensaio sobre a Indústria Cultural no Brasil (1971)4 -, logo evidencia, desde a abertura até a conclusão, a sondagem experimental quanto ao rendimento interpretativo de paradigmas semióticos em meio à análise do programa de auditório. Busquei aproximar a sociologia de procedimentos que me pareciam ensejar a apreensão refinada do material expressivo, com vistas à leitura matizada da prática cultural. Assim, por exemplo, em vez de empreender o resgate algo convencional dos liames entre o programa e o público, apenas com base em índices de audiência, esbocei análise que dava espaço e relevo ao cenário, à indumentária, à gestualidade, à postura corporal. Eis um exemplo da tensão com a qual tínhamos de lidar: o embate entre a dominância marxista e o influxo de recentes abordagens e procedimentos.

A aprendizagem ocorreu num momento em que não havia sistema de cotas, tampouco a rede de universidades federais. Ali presenciamos a emergência de um sistema de financiamento. Brindado com bolsa da Coordenação de Aperfeiçoamento de Pessoal de Nível Superior (CAPES), fui dos primeiros a receber tal benefício.

A recepção inicial de Bourdieu tem muito a ver com o fato de que um contingente expressivo de pós-graduandos da geração foi estudar no exterior: a maioria nos Estados Unidos, um grupo restrito na Europa, uns e outros beneficiários de bolsas de estudo, nacionais e estrangeiras. Nos Estados Unidos, ocorreu a formação da leva pioneira de cientistas políticos. Por conta da estadia parisiense, tive formação peculiar se comparado aos colegas treinados no campus norte-americano.

Em paralelo ao clima intelectual, é forçoso restituir a fisionomia política da época. Vivíamos em plena ditadura militar. A recepção de Bourdieu, nas décadas de 1970 e 1980, coincidiu com um período especial do regime militar. Corresponde à presidência do General Ernesto Geisel (1974-1979) e do General João Figueiredo (1979-1985); à greve dos trabalhadores em 1978; à emergência de Lula como líder nacional; à revogação do AI-5,

\footnotetext{
4 MICELI, Sérgio. A Noite da Madrinha: Ensaio sobre a Indústria Cultural no Brasil. São Paulo: Perspectiva,
} 1971. $368 \mathrm{p}$. 
em 1979; às eleições de 1982, quando foram eleitos governadores de oposição como Franco Montoro, em São Paulo; às eleições de 1985, com a chapa Tancredo-Sarney; à morte de Tancredo e ao governo Sarney; à Constituição de 1988. Hoje ainda nos surpreende que o regime militar tenha, no período, contribuído para viabilizar financeira e institucionalmente as ciências sociais. De um lado, os militares perseguiam, prendiam e exilavam professores; de outro, subsidiavam a institucionalização da área.

Estávamos imersos em conjuntura tumultuada, complexa e contraditória. Em pleno regime militar, havia política educacional de expansão do ensino superior, linhas de investimento em formação e pesquisa em ciências sociais, redes de financiamento inclusivas: a expansão da Financiadora de Estudos e Projetos (Finep), da CAPES, do Conselho nacional de Desenvolvimento Científico e Tecnológico (CNPq), etc. Em contraste com tais iniciativas, o governo aposentava compulsoriamente Florestan Fernandes, Fernando Henrique Cardoso e outros mestres prestigiosos, muitos deles tendo sido forçados ao exílio. Os militares brasileiros não destruíram a universidade, tal como sucedeu na Argentina ou no Chile. Pelo contrário, eles ajudaram a erguer financeira e institucionalmente o sistema universitário brasileiro.

Tais fatos provocaram estupefação na audiência francesa. São evidências desconcertantes difíceis de lidar, mas sobre as quais qualquer cientista social deve refletir: as ciências sociais foram emergindo em resposta aos incentivos propiciados por uma política pública, ainda que se possa adicionar ao cenário de época as contribuições das fundações privadas norte-americanas, em especial da Fundação Ford. No entanto, o apoio da Ford foi mais decisivo à construção institucional da ciência política e da antropologia, tangencial no caso da sociologia. Florestan nunca aceitou recursos da Ford, conforme atestam evidências dessa postura; embora arredio ao auxílio de fundações privadas no financiamento da sociologia, acedeu ao apoio da Unesco de subvencionar os estudos das relações raciais no país.

Ao fincar as estacas do universo intelectual da época, emergem as linhas de força do tipo de formação acadêmica a que estava submetida a geração. A universidade operava como uma espécie de espaço protegido durante o governo militar, em paralelo à alternância de altos e baixos na repressão sombria da ditadura. Com frequência chegávamos à universidade e ficávamos cientes da prisão de colegas e de docentes, por 
vezes éramos instados a prestar assistência aos familiares dos detidos. Atmosfera pesada e difícil de peitar. Assim, com 29 anos, o fato de ter sido brindado com bolsa do governo francês me conferia status de privilégio.

Outra dimensão decisiva tem a ver com as características morfológicas do contingente atraído pelas ciências sociais na geração pioneira, formada ao longo das décadas de 1930, 1940 e 1950. Na Universidade de São Paulo, o corpo discente nas disciplinas recém instituídas incluía uma parcela expressiva de filhos de imigrantes e de mulheres. Enquanto nas Faculdades de Medicina e de Direito, a parcela de filhos de imigrantes nunca passou de $1 \%$ até os anos 1950, nas ciências sociais os filhos de imigrantes eram um terço dos estudantes (32\%), as mulheres quase isso (28\%), escores ainda em linha ascendente nos anos subsequentes. Por conseguinte, o campo emergente das ciências sociais se caracterizava, nos anos 1960 e 1970, pela morfologia social consideravelmente distinta daquela predominante no recrutamento das profissões liberais tradicionais.

A estadia dos mestres franceses na Universidade de São Paulo reforçou o prestígio da sociologia e viabilizou a abertura aos estudos culturais em especial. Após o retorno de Roger Bastideà França, em 1959, a sociologia da cultura perdeu espaço em favor do macroprojeto de investigação cujas diretrizes Florestan impunha aos assistentes e aos alunos. Ele havia formulado o projeto tentacular de análise da formação histórica das classes sociais no Brasil contemporâneo, que serviu de alavanca à voga da sociologia do desenvolvimento como paradigma explicativo. Os mestrandos da turma, inclusive os que tinham outros orientadores, éramos instados a uma conversa preliminar antes da escolha dos objetos de tese. Na sala, me deparei com a lista extensa de tópicos assinalados a giz na lousa; era forçoso escolher o tema dentre os nomeados. A 'escolha' estava adstrita à lista. Após a leitura esticada dos tópicos, me dei conta de que o único assunto que de fato me interessava era a revista do Iseb, pois me daria acesso aos intelectuais cariocas -, não por acaso, o último ponto da lista. A escolha foi acolhida, mas não pude levar a cabo por diversas circunstâncias, inclusive pela aposentadoria compulsória do próprio Florestan e de outros docentes, entre os quais meu orientador, Octavio Ianni.

Meses após a rebordosa, a reitoria começou a pressionar o departamento de sociologia no intento de acelerar a produtividade, ou seja, o término das teses. O número 
de docentes havia encolhido; nos sentíamos na obrigação de colaborar. Em vista de tais constrições, fui estimulado a desenvolver a dissertação a partir do artigo que vinha redigindo acerca de programas de auditório na televisão, algo impensável na conjuntura anterior. Florestan era uma figura formidável, acolhedor, generoso, afável com os estudantes, respeitado, admirado, empenhado nas atividades do departamento, exercendo com firmeza a liderança institucional e intelectual.

Em meio às circunstâncias da recepção de Bourdieu no Brasil, quero falar um pouco sobre minha biografia para que vocês possam entender o papel dos intermediários nesse processo. Estou me referindo aos colegas Renato Ortiz, Afrânio Garcia Junior e Maria Andrea Loyola, entre outros. A morfologia social desse grupo constitui subsídio indispensável à inteligibilidade da recepção de Bourdieu.

Após haver concluído ciências sociais na Pontifícia Universidade Católica (PUC) do Rio de Janeiro (1964-7), já bolsista da Capes, cheguei a São Paulo em dezembro de 1967, onde cumpri os cursos exigidos na pós-graduação, tendo concluído o mestrado em 1971. Em 1974, bolsista do governo francês, viajei a França para me doutorar - nesse momento, trabalhava como professor de sociologia no departamento de ciências sociais da Fundação Getúlio Vargas (FGV-SP). Dito de outro modo, os mediadores acima mencionados estavam, então, à margem da sociologia dominante no país. Embora lotado numa instituição prestigiosa, fora aluno na Universidade de São Paulo, estava inscrito no doutorado, mas ainda não pertencia ao quadro docente na disciplina. Renato Ortiz começou na área de estudos agrícolas, em seguida cursou quatro anos na Escola Politécnica da Universidade de São Paulo, antes de viajar a França, onde obteve um diploma equivalente ao nosso mestrado - Diplôme d'études supérieures (DES) - com Edgard Morin, e o título de doutor de terceiro ciclo sob tutela de Roger Bastide, em sociologia da religião. De regresso ao Brasil, Ortiz lecionou, sucessivamente, no Nordeste, em Minas Gerais, tendo ingressado no departamento de sociologia da Universidade Estadual de Campinas (Unicamp) apenas em 1988. Nesse ano, fui convidado a ingressar no departamento de sociologia da Universidade de São Paulo, tendo então deixado o posto docente na pós-graduação em sociologia da Unicampe a posição de professor titular na Fundação Getúlio Vargas. Andrea Loyola fez doutorado com Alain Touraine, bem antes de se juntar aos pesquisadores na órbita de Bourdieu, do qual eu fazia parte. Até esse 
momento, a maioria dos brasileiros com doutorado em sociologia na França trabalhou com Touraine - o qual orientou doze teses de doutorado de colegas nos anos 1970. Fui o primeiro a romper a corrente, tendo concluído o doutorado com Bourdieu em 1978. Moacir Palmeira (doutorado na França com François Bourricaud), José Sérgio Leite Lopes e Afrânio Garcia, jovens docentes na pós-graduação em Antropologia Social criada fazia pouco no Museu Nacional, no âmbito da Universidade Federal do Rio de Janeiro, também estavam distantes da sociologia uspiana. Moacir havia se diplomado na Escola de Sociologia e Política da PUC carioca; José Sergio e Afrânio se formaram economistas antes da reconversão à antropologia

Bourdieu foi divulgado no Brasil por intermediários que estavam, de algum modo, mobilizando suas obras e o paradigma explicativo como instrumento de luta em esporte de combate intelectual. Bourdieu não ingressou no país por cima, pelos sediados na sociologia uspiana, mas pelas margens, por conta de mediadores ainda posicionados longe da autoridade sociológica reconhecida. Ora, era diminuto o interesse pelos textos de Bourdieu por parte da sociologia paulista; havia inequívoca hostilidade em relação a sua obra. Minha introdução à antologia A economia das trocas simbólicas (1974) permite vislumbrar tal animosidade. Nesse texto que vivenciei como um tour de force, pretendia demonstrar que o autor estava à altura dos fundadores da tradição sociológica contemporânea. Em diversas passagens, procuro frisar os laços dele com o legado de Marx, Durkheim e Weber. O lastro tríplice intentava sustentar a filiação prestigiosa, ou melhor, reivindicar legitimidade para o nome desconhecido no país. Era a estratégia de lograr receptividade por meio de figuras interpostas, por procuração - no caso, os clássicos que compõem até hoje o núcleo da licenciatura em ciências sociais na Universidade de São Paulo.

Em 1972, em seguida à defesa do mestrado sobre o programa de auditório de Hebe Camargo, já havia começado a preparar a antologia publicada em 1974, sob chancela da Perspectiva, editora então prestigiosa no campo das humanidades. O volume contava com introdução circunstanciada, um tanto excessiva ${ }^{5}$, que, em retrospecto, talvez encontre

\footnotetext{
5 MICELI, Sergio. A força do sentido. In: Sergio Miceli. (Org.). A economia das trocas simbólicas. São
} Paulo: Editora Perspectiva, 1974, p. I-LXI. 
justificativa no empenho de atribuir estatuto teórico à obra: era imperioso demonstrar a pertinência e a potência de conceitos como "campo" e "habitus", ainda na primeira dentição. Desde o começo do texto, quis lidar com a ideia de "campo", tal como formulada nos textos da fase inicial - e não no registro de voltagem complexa com que é manejada em Meditações Pascalianas $(1997)^{6}$, por exemplo. Ao tempo em dirigi a Editora da Universidade de São Paulo (Edusp), entre 1994 e 1999, publiquei a tradução de Ce que parler veut dire (edição francesa, 1982)7, com o título A Economia das Trocas Linguísticas (Edusp, 1998) ${ }^{8}$, o subtítulo da obra. Escrevi breve introdução de cinco ou seis páginas; por ocasião do estágio como professor convidado na França, por iniciativa dele, chamou atenção para o tratamento desigual e frisou o investimento da primeira vez. As cinquenta páginas da coletânea inicial minguaram agora para cinco. Ora, minha situação acadêmica se alterara de modo drástico.

O livro com selo Edusp se enquadra em momento subsequente da recepção de Bourdieu, quando me pareceu dispensável a muleta de um arrazoado que facilitasse a leitura. Na ocasião, reiterou ter apreciado a primeira introdução; não lia português, apesar de bom domínio do espanhol por ser originário de região próxima à Espanha - talvez atinasse algo de português. De início, escrevia em português os rascunhos dos capítulos; ele devia ter algum conhecimento para fazer os comentários que me transmitia pelo telefone e por escrito.

O período de doutorado teve quebras: residi em Paris em 1974 e 1975, voltando ao Brasil em seguida; retornei a França com a tese acabada em português; permaneci o ano de 1978 para aprontar o texto da versão francesa; defendi a tese em francês em dezembro desse ano. O trabalho foi publicado no Brasil em 1979, na coleção Corpo e Alma do Brasil, dirigida por Fernando Henrique Cardoso - que me fez o convite na festa de comemoração do doutorado brasileiro. Em 1981, a tese foi editada em francês, por decisão de Bourdieu,

6 BOURDIEU, P. Meditações Pascalianas. Tradução: Sérgio Miceli. Rio de Janeiro: Bertrand Brasil, 2001. $324 \mathrm{p}$.

7 BOURDIEU, P. Ce que parler veut dire: l'économie des échanges linguistiques. Paris: Fayard, 1982. 244 p.

8 BOURDIEU, P. A Economia das Trocas Linguísticas: O que Falar Quer Dizer. Prefácio Sérgio Miceli. São Paulo: Editora da Universidade de São Paulo, 1998. 183 p. 
financiada pela Maison des Sciences de l'Homme, com chancela da Presses Universitaires de Grenoble, volume inaugural da coleção Brasilia.

Em 1984, fui eleito secretário-geral da Associação Nacional de Pós-Graduação e Pesquisa em Ciências Sociais (Anpocs), tendo exercido dois mandatos, até 1988. Eis o ano milagroso da abertura democrática no Brasil, e do começo como professor no programa de doutorado em ciências sociais da Unicamp. A essa altura, já se havia encerrado o período inaugural de recepção de Bourdieu; fui com vagar me aproximando, como docente, do stablishment sociológico, em meio a transformações de peso no interior do campo intelectual e acadêmico. O governo militar ensejou a expansão das ciências sociais impulsionadas pelas universidades federais recém criadas -, em paralelo à gestação do sistema nacional de pós-graduação e ao crescimento vertiginoso das agências federais de financiamento à pesquisa e à formação doutoral. Tais mudanças propiciaram a crescente identidade disciplinar da antropologia e da ciência política, ora despregadas da sociologia -, mais dependentes da Fundação Ford do que a sociologia.

A difusão da obra de Bourdieu tomou corpo em espaços institucionais à margem dos centros dominantes das ciências sociais no Brasil, por conta da mediação de pesquisadores jovens que estavam em começo da carreira acadêmica, os quais ocupavam posições periféricas ao que se considerava a alma mater da sociologia, a Universidade São Paulo. Eu lecionava numa escola de administração, afastada do reduto sociológico. A ênfase na condição subalterna dos mediadores chocou os franceses, em particular os doutorandos na audiência. Os colegas envolvidos no trabalho de difusão estavam, nos anos de 1970 e de 1980, situados em posições de segundo time no tocante ao perfil hierárquico da área. Tal fato não diminui o Museu Nacional ou a Fundação Getúlio Vargas. Quis mapear a inserção dos mediadores em relação ao mainstream sociológico - fato crucial, tendo em vista que Bourdieu sempre se definiu como sociólogo e ganhará notoriedade na disciplina em escala mundial. Éramos jovens diplomados com acesso a um treinamento acadêmico sofisticado - privilegiados sem dúvida, mas desclassificados em termos de inserção institucional - espécie híbrida de classés/declassés. Uma fornada de cientistas sociais debutantes, dotados de cabedal requintado e, ao mesmo tempo, ainda relegados à posição subalterna no bojo da disciplina. Ninguém estava à vontade no tocante ao status acadêmico e disciplinar. Insisto nesse traço porque não me parece 
apropriado recuperar a história da recepção de Bourdieu com base na conjuntura do campo intelectual moldada na década de 1990. Ao longo dos anos de 1980, fomos tendo acesso às posições prestigiosas e, de modo concomitante, foram se transformando as condições internas moldando o trabalho de recepção em bases distintas. Como presidente da Edusp, tive condições de publicar a coletânea de textos extraídos da Revista Líber, editada por Bourdieu 9, A Economia das Trocas Linguísticas (1998), iniciativas indissociáveis de uma posição institucional confortável. Vale sublinhar o registro, fui convidado para ingressar como docente na Universidade de São Paulo em 1988 -, aos 43 anos de idade e já livre docente.

Por fim, como líamos a obra de Bourdieu e qual o impacto na aprendizagem? Dois livros deram a chacoalhada. Le Métier de Sociologue - publicado na França em 1968 pela trinca autoral de Bourdieu, Passeron e Chamboredon - era lido em grupo em atitude de contrição. O manual logo adquiriu o status de modelo de excelência incontornável, guia de referência às práticas do que passamos a considerar como o ramerrão indispensável à profissão de sociólogo. O frescor intelectual se juntava ao feitio ambicioso da proposta: manancial de teoria sociológica, repositório de cauções empíricas. Os exemplos aí mobilizados provinham de pesquisas, muitas delas a cargo de cientistas sociais norteamericanos, que não constavam da bibliografia corrente. Em registro inusitado, a obra mesclava domínio da tradição teórica e pedágio à investigação empírica, além de haver ampliado o repertório de referências, entre os quais os trabalhos de Erving Goffman, de etnometodologia (Garfunkel), de etnociência (Stephen Tyler), que nunca havíamos lido. A iniciação na ciência social norte-americana foi estimulada por esse manual, repertório de autores, de textos e de correntes a que tínhamos acesso pela primeira vez. O volume provocou certa euforia intelectual, fazendo as vezes de vade-mécum que nos autorizava a misturar métodos e procedimentos que, até então, pareciam inconciliáveis. Na Universidade de São Paulo, estudantes interessados em pesquisa empírica eram amiúde detratados como positivistas. Os autores do manual viabilizaram o consórcio entre ambição teórica e lastro empírico.

9 Líber 1, 1997. 
A Reprodução (publicado em francês em 1970) ${ }^{10}$, por outro lado, teve efeito controverso na época. Os que já leram a obra talvez concordem comigo: para a nossa geração, o livro soou com estrondo de denúncia. Trata-se de um texto de leitura pedregosa, em parte por conta da deficiente tradução brasileira. Não obstante, o livro foi castigado pela rigidez e pelo dogmatismo. O fascínio pelo trabalho do mestre não tolheu o discernimento.

As obras do autor desencadeavam pulsões contraditórias, em meio as quais se vislumbrava a construção de um objeto próprio no campo da sociologia da cultura. Aliás, Bourdieu encorajava os orientandos a se familiarizar com história social da arte - não se podia fazer sociologia da vida intelectual sem o cabedal das tradições na disciplina. Ele também nos libertava da obediência estrita aos modelos canônicos em voga na Universidade de São Paulo: a crítica literária, a estética filosófica e a história da arte formalista. Aqueles interessados no estudo da produção cultural puderam se valer dele e desguiar do jugo exercido pelos paradigmas então prevalecentes. Ficávamos isentos da louvação aos autores canônicos da sociologia das superestruturas, em especial, Karl Mannheim - entidade reverenciada no espaço universitário da época. Na arguição de minha tese de doutorado no Brasil, alguns integrantes da banca cobraram pela omissão de Mannheim -, cujas obras de fato não me atraíam. Ficamos livres de Mannheim pela sintonia com a teoria sociológica hard em detrimento dos esquematismos acionados pela história das ideias. Os textos de Mannheim ancoram as paráfrases empreendidas pelo chamado pensamento social; os estudos de Bourdieu espicaçam a sociologia empírica da produção cultural e dos intelectuais. Indústria cultural, televisão, arte, intelectuais, eis alguns dos assuntos relegados na bolsa de valores da sociologia brasileira da época. A prensa de Florestan na escolha do tema de dissertação brecou a feitura de estudo sobre o movimento tropicalista tal como havia imaginado.

A segunda onda de recepção dos trabalhos de Bourdieu no país sucedeu em meio a mudanças de peso: expansão das publicações em ciências sociais; criação de novas associações científicas - em especial a Anpocs, com subvenção da Fundação Ford, a

1o BOURDIEU, P.; PASSERON, J. La reproduction: Éléments d'une théorie du système d'enseignement. Paris: Les Éditions de Minuit, coll. «Le sens commun», 1970. 284 p. 
Associação Brasileira de Antropologia (ABA) e a rediviva Sociedade Brasileira de Sociologia (SBS); profissionalização acelerada dos cientistas sociais - entre os formandos da minha turma da PUC no Rio de Janeiro, em 1967, a maioria encontrou empregos relacionados à sociologia; autonomização das disciplinas e especialização temática.

Essa vaga também derivou do renascimento da sociologia da cultura no país. Prova inequívoca de renovação são os dois volumes da História das Ciências Sociais no Brasil, publicados, respectivamente, em 1989 e 1995, frutos de pesquisa coletiva. Os textos aí coligidos foram escritos por integrantes da equipe multidisciplinar que coordenei, mesclando historiadores, sociólogos, antropólogos, cientistas políticos, - Heloísa Pontes, Fernanda Peixoto, Fernando Limongi, Maria Hermínia Tavares de Almeida, Silvana Rubino, Maria Arminda do Nascimento Arruda, Lília Schwarcz, Silvana Rubino, Maria da Gloria Bonelli, Maria Cecília Forjaz. Quase todos jovens mestrandos cujas dissertações se nutriram dos mestres contemporâneos no assunto em paralelo ao impacto crescente das obras de Bourdieu. A bibliografia ora disponível em sociologia da cultura se havia dilatado, abarcando correntes e autores de variado perfil teórico; Norbert Elias, Fritz Ringer, Raymond Williams, Michel Foucault, Edward Thompson e outros que começaram a circular concomitantemente à absorção do mestre francês.

Em suma, a recepção de Bourdieu no Brasil foi uma arena de confronto, um instrumento de combate e competição por parte de jovens que estavam à margem do stablishment sociológico e que se valeram de tal acicate no intento de lograr espaço e reconhecimento. Não estávamos apenas enfeitiçados pela obra. Havia, ademais, o desígnio de converter as inovações em trunfos da prática intelectual. Bourdieu torna-se inteligível no aceso das disputas em curso na sociologia brasileira, por meio de obras, conceitos e procedimentos que adquirem sentido e pungência no interior de um campo de lutas. Não basta incensá-lo, tampouco converter textos em fetiches. Quis transmitir o recado de que a imensa admiração não estava infensa às pulsões e interesses de quem estava se iniciando no ofício. 